\title{
Production of Dual Fuel Biodiesel as an Alternative Fuel for Diesel Engine with Improved Cold Flow Characteristics
}

\author{
Chetan Sablok* and Navdeep Sharma Dugala \\ Department of Automobile Engineering, Chandigarh University, Mohali - 140413, Punjab, India; \\ chetan.sablok6@gmail.com,navdeepdugala@gmail.com
}

\begin{abstract}
Objective: To produce dual fuel biodiesel, where different percentage of blends was taken to check the physio and chemical properties of the dual fuel. Analysis: As we all know our society is hugely dependent on the fossil fuels, which results in the higher cost of petroleum products, high emissions of $\mathrm{HC}, \mathrm{CO}_{2}$ and Nox. To bring down the dependency on the conventional fuels and to reduce the various types of emissions new sources of alternate energy must be developed. Biodiesel is becoming one of the most prominent options among the other alternate energy resources, due to its economic and environmental factors. Finding: Biodiesel is an alternative fuel which can be used with mineral diesel without any modification or small modifications to the engine. The methyl ester of vegetable oil (edible and non-edible oil) and animal fat are known as biodiesel. In the past researchers had done blending of biodiesel made from single vegetable oil with the mineral diesel and left the scope of work on the biodiesel made from the combining of two different types of biodiesel blended with diesel in different mixing ratios. Improvement: The methyl esters of seed oil are produced through transesterification process. The experiment was done to produce dual fuel, where different percentage of blends was taken to check the physio and chemical properties of the dual fuel. The cold flow properties of dual fuel were found to be optimal at 50:50 blends.
\end{abstract}

Keywords: Cloud Point, ColdFlow Properties, Jatropha Biodiesel, Mahua Biodiesel, Pour Point, Transesterificaion

\section{Introduction}

In the recent years the extensive use of petroleum fuel has led to the depletion of fossil fuel reserves, due to increase of human population, the ever increasing demand of industrialization increasing, which indirectly leads to the rising price of the fossil fuels. The burning of the petroleum products results in the emissions of $\mathrm{HC}$, $\mathrm{CO}_{2}$ and Nox emissions. Due to the above mentioned reasons the alternative energy resources are becoming more attractive as they are renewable, sustainable and produce less or no emissions than the conventional fuel. Biodiesel is an alternative fuel which is produced from the vegetable oil which could be edible and non- edible and animal fats. Biodiesel is produced from different methods like Blending, Emulsification, Pyrolysis and
Transesterification ${ }^{1}$. The most common method for producing biodiesel is Transesterification because it is the simplest method for the production of biodiesel ${ }^{2}$. In the past researchers had done blending of biodiesel made from single vegetable oil with the diesel and left the scope of work on the biodiesel made from the blending of two different biodiesel blended with diesel in different mixing ratios ${ }^{3}$. Dual biodiesel reduces the emissions and improves the cold flow properties of the biodiesel. The cold flow properties of Jatropha Biodiesel are better ${ }^{4}$, so in this research weve selected the Jatropha biodiesel and Mahua biodiesel for the preparation of the dual fuel biodiesel. Both Mahua raw seed oil and Jatropha raw seed oil have prominent Free Fatty Acid (FFA) content which is around $19 \%-20 \%$. In order to reduce the FFA of both the raw oil pre-treatment process is required ${ }^{5}$. The yield

*Author for correspondence 
of the oil is depends upon the various parameters like oil temperature, temperature of reaction, oil to alcohol ratio, type of catalyst and concentration and purity of the reactants. Methanol is used instead of the Ethanol for the preparation of the biodiesel as methanol has better reactivity than the ethanol. Acid catalyst $\left(\mathrm{H}_{2} \mathrm{SO}_{4}\right)$ is used during the pre-treatment process and base catalyst $(\mathrm{KOH})$ is used during the transesterificaion process, the reason for this is the high percentage of the FFA content in the seed oils, because if we directly use the base catalyst the reaction will not take place properly instead the formation of soap takes place and the catalyst is no longer available for the reaction ${ }^{6}$. Mahua biodiesel and Jatropha biodiesel has better combustion and emissions properties than that of the conventional mineral diesel ${ }^{7}$. Jatropha biodiesel have good cold flow properties than Mahua biodiesel. As order to improve the cold flow characteristics of the Mahua biodiesel we blend the Mahua biodiesel with Jatropha biodiesel in different blending, in order to find out optimum blending ratio for dual fuel. In this experimental research we've prepared the dual fuel biodiesel with the non edible vegetable oil as to have the good cold flow properties of the biodiesel and which stands upon the ASTM.

\section{Material and Method}

The raw Mahua seed oil and the raw Jatropha seed oil was purchased from the Himani International, Delhi and the methanol (99\% pure) was purchased from the Oswal Scientific Stores, Chandigarh. The acidic catalyst used for the pre treatment was $\mathrm{H}_{2} \mathrm{SO}_{4}$; the base catalyst used for the transesterification was $\mathrm{KOH}$ (Potassium hydroxide) which is present in pellet form. The experiment was conducted in the chemical laboratory which is in the premises of Chandigarh University. The experiment was conducted using the laboratory scaled equipment which is as follows: 1 liter glass beaker, stirring glass rod, water bath (temperature $100^{\circ} \mathrm{C}$ ).

\subsection{Preheating}

The raw Mahua seed oil and the raw Jatropha seed oil was pre heated separately at a temperature of $90^{\circ}-100^{\circ} \mathrm{C}$ for 30 minutes and was stirred manually with the help of glass stirring rod at the time interval of 5 minutes regularly to eliminate the any water content and to remove any unwanted dust particles and then filtering the heated oil using the 5 micron filter paper.

\subsection{Pretreatment}

The reason for choosing the two step process for producing biodiesel is because both the raw seed oil Mahua and Jatropha seed oil have the prominent Free Fatty Acid (FFA) content which is around 19\% and after the pre treatment process the FFA fall under $1 \%$ which will result in better yield of the oil.

Each sample of both the raw oil was made using different alcohol to oil ratio.

\section{Sample 1: Mahua raw seed oil}

Preheated Mahua seed oil is used for the pre treatment process, $75 \% \mathrm{v} / \mathrm{v}$ methanol to oil and $1.5 \% \mathrm{v} / \mathrm{v}$ sulfuric acid which act as a acidic catalyst is used for the process, all the reactants were poured into the glass beaker and the reaction was carried out for the 2 hours in the water bath, at temperature ranging from $60^{\circ} \mathrm{C}-80^{\circ} \mathrm{C}$ while stirring the mixture at every 5 minutes of interval manually with the help of glass rod. After the reaction, the mixture is poured into the separating funnel and giving it a settling time of 1 hour.

$$
\mathrm{R} 1 \mathrm{COOH}+\mathrm{ROH}=\mathrm{R} 1 \mathrm{COOR}+\mathrm{H} 20
$$

(Pre treatment reaction equation)

\section{Sample 2: Jatropha raw seed oil}

Pre heated Jatropha seed oil is used for the pre treatment process, $50 \% \mathrm{v} / \mathrm{v}$ methanol to oil and $1 \% \mathrm{v} / \mathrm{v}$ sulfuric acid which act as a acidic catalyst is used for the process, all the reactants were poured into the glass beaker and the reaction was carried out for the 1:30 hours in the water bath, at temperature ranging from $60^{\circ} \mathrm{C}-80^{\circ} \mathrm{C}$ while stirring the mixture at every 5 minutes of interval manually with the help of glass rod. After the reaction the mixture is poured into the separating funnel and giving it a settling time of 1 hour as shown in Figure 1.

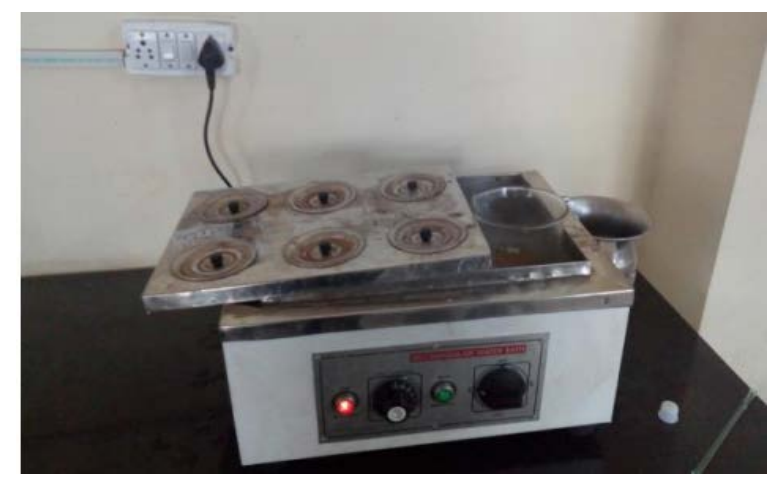

Figure 1. Pretreatment process. 


\subsection{Transesterification Process}

Transesterification is the process in which the displacement of alcohol from an ester by another alcohol takes place. In this the step, firstly pre treated oil is heated up to $60^{\circ} \mathrm{C}$ in the water bath, in order to eliminate the moisture.

\section{For Sample 1: Mahua raw seed oil}

Firstly the pre treated oil is heated as we discussed earlier, a methoxide solution is prepared using the 50\% v/v oil to methanol, $1 \%$ w/v base catalyst Potassium Hydroxide (KOH) which is present in pellet form. Methanol and $\mathrm{KOH}$ are mixed in a conical flask with the cork on top and stirred vigorously until the pallets of the $\mathrm{KOH}$ gets dissolved in the methanol. Add this methoxide solution to the pre treated oil which is being heated in the water bath at $60^{\circ} \mathrm{C}$ and carry out the reaction for 45 minutes; the temperature varies from $60^{\circ} \mathrm{C}$ to $70^{\circ} \mathrm{C}$, while stirring mixture manually at an interval of every 5 minutes. The mixture is been allowed to settle for overnight in a separating funnel to separate the biodiesel and glycerol. After overnight settling two layers will form, one of biodiesel (top) and the other one are of glycerol (bottom).

\section{For Sample 2: Jatropha raw seed oil}

For the second step to produce biodiesel we followed the same process as we followed during the production of Mahua biodiesel.

For the preparation of methoxide solution, $20 \%$ oil to methanol, $1 \% \mathrm{w} / \mathrm{v}$ base catalyst Potassium Hydroxide $(\mathrm{KOH})$ which is present in pellet form is used. Methanol and $\mathrm{KOH}$ are mixed in a conical flask with the cork on top and stirred vigorously until the pallets of the $\mathrm{KOH}$ gets dissolved in the methanol.

After adding this methoxide solution to the pretreated oil, the reaction is carried for 1 hour at a temperature which varies from $60^{\circ} \mathrm{C}-70^{\circ} \mathrm{C}$ in a water bath while stirring the mixture at every 5 minutes of interval as shown in Figure 2. The mixture is being allowed to settle for overnight in a separating funnel as shown in Figure 3 and then the layer of biodiesel and glycerol is bringing separated out as shown in Figure 4.

\subsection{Water Washing}

After separating out the biodiesel from the glycerol, some amount of glycerol is still present due to cold weather conditions, in order to remove the unwanted amount of

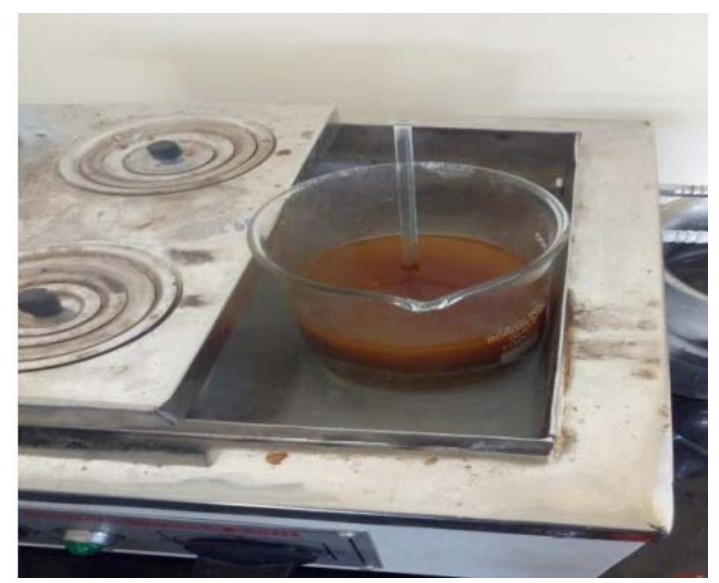

Figure 2. Transesterification process.

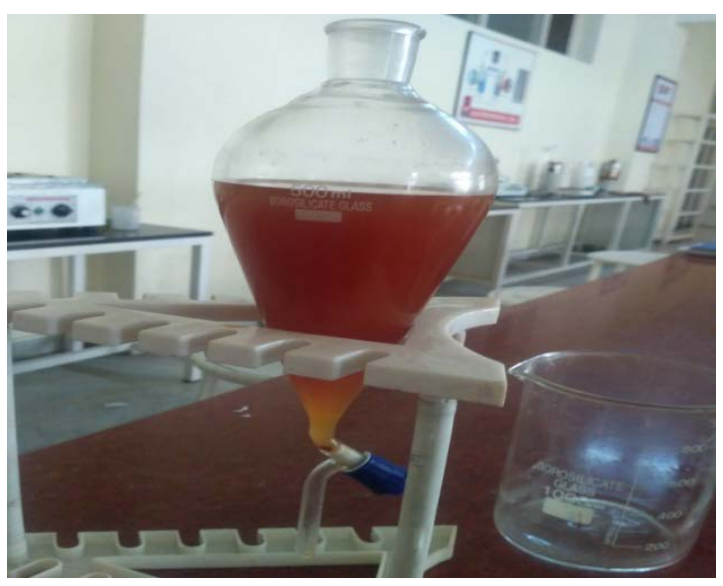

Figure 3. Biodiesel left for settling.

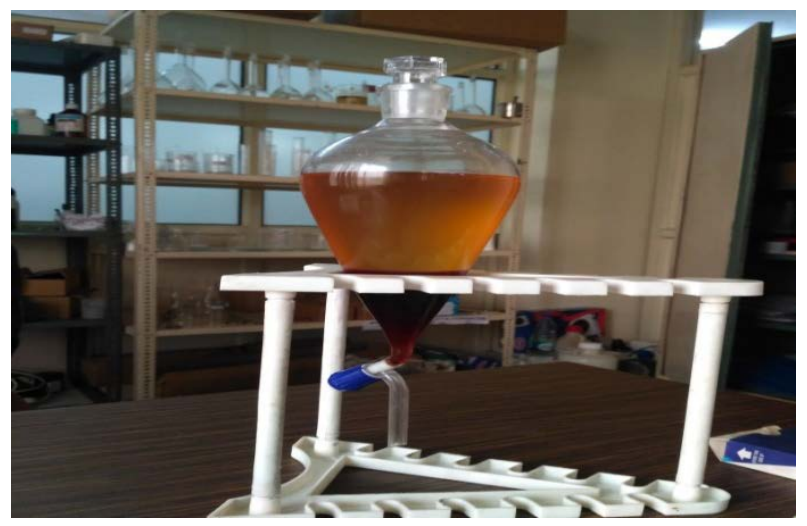

Figure 4. Biodiesel after overnight settling.

glycerol hot water washing method is used as shown in Figure 5. In this method we add the hot boiled water in the methyl ester which is kept inside the separating funnel and eliminate the layer of glycerol after mixing it with the 
methyl ester form the bottom by opening the outlet valve. Keep repeating this process until we get the clear water layer at bottom as shown in Figure 6. In the end again heat the methyl ester up to $100^{\circ} \mathrm{C}$ in order to remove any water moisture left.

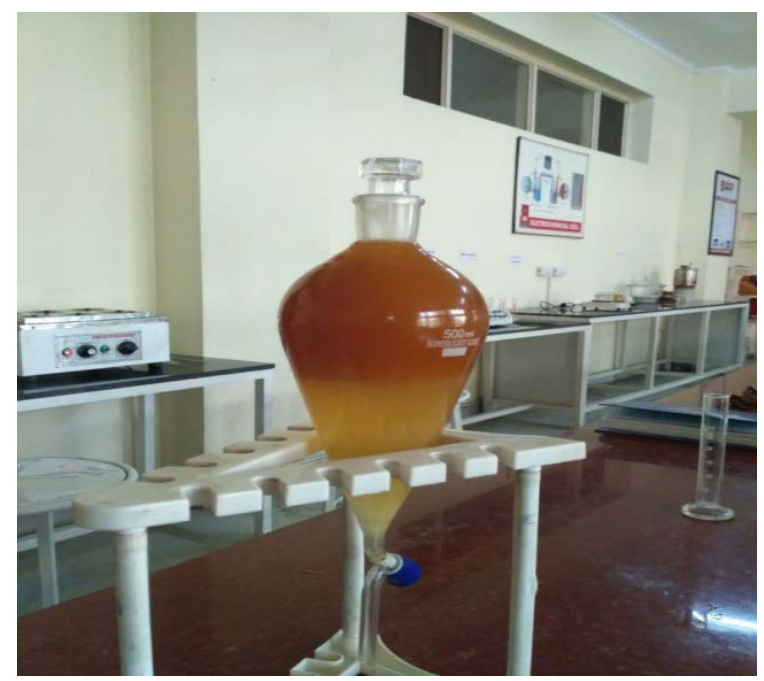

Figure 5. Waterwashing process.

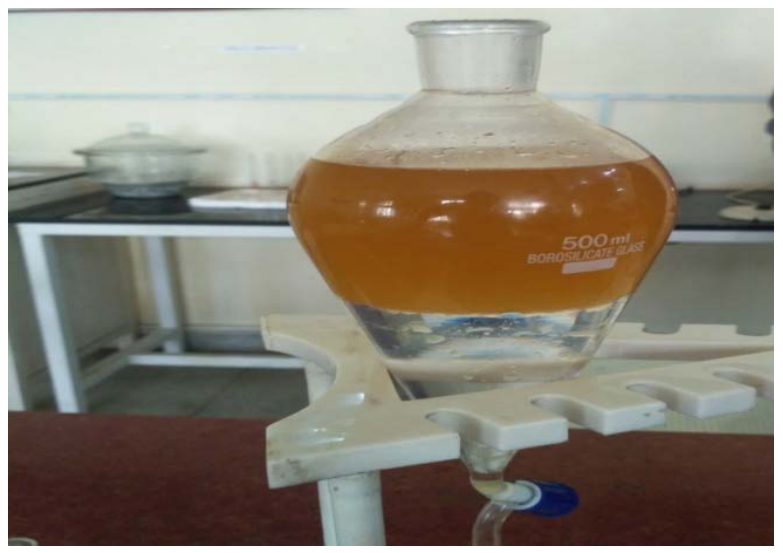

Figure 6. After completing water washing process.

\subsection{Improving the Cold Flow Properties}

As biodiesel is produced from the feedstock like vegetable oil (edible or non-edible) and animal fats which is high in fats especially the saturated ones, creates problem during the cold weather conditions ${ }^{8}$. In the cold running conditions biodiesel faces some cold flow problems like gelling, chocking the injectors etc ${ }^{9}$. These properties of biodiesel can be solved by blending of another biodiesel into it, in order to get the desired properties of the biodiesel which overcome the cold flow problem. As to overcome these problems we use some additives to get the desired cold flow characteristics of the biodiesel. Mahua biodiesel doesn't show the good cold flow characteristics in order to improve its cold flow properties we blend the Mahua biodiesel with Jatropha biodiesel which is known for its good cold flow properties ${ }^{10}$. Different blends of dual fuel were prepared, a blend of $50 \%$ v/v i.e. Mahua biodiesel and $50 \%$ Jatropha biodiesel shows the desired physio chemical properties of the biodiesel which could bear the cold weather conditions.

\subsection{Methodology}

In order to determine whether the biodiesel has the physio chemical properties within the permissible limit it is necessary to find out the cold flow characteristics of samples using the required lab apparatus and experiments. The temperature at which cloudiness starts appearing in the biodiesel is the cloud point and the temperature at which the biodiesel becomes half solid means loses its tendency to flow is pour point ${ }^{11}$.

\section{Result and Discussions}

The table shows the Physio chemical Properties of Mahua biodiesel and Jatropha biodiesel as shown in Table 1.

Table 1. Physio chemical properties of Mahua biodiesel and Jatropha biodiesel

\begin{tabular}{|c|c|c|c|c|c|c|c|c|}
\hline Sr. no & Property & Raw Mahua Oil & Raw Jatropha Oil & M.B.D & J.B.D & $\begin{array}{l}\text { (Dual biodiesel) } \\
\text { M50 J50 }\end{array}$ & $\begin{array}{l}\text { ASTM } \\
(6751-02)\end{array}$ & $\begin{array}{l}\text { Mineral } \\
\text { Diesel }\end{array}$ \\
\hline 1. & Density $\left(\mathrm{kg} / \mathrm{m}^{3}\right)$ & 980 & 985 & 937.3 & 925 & 930.3 & $850-870$ & 830 \\
\hline 2. & Specific Gravity & .980 & .985 & .937 & .925 & .930 & $.850-.870$ & .830 \\
\hline 3. & $\begin{array}{l}\text { Kinematic } \\
\text { Viscosity (cst) }\end{array}$ & 24.99 & 24.76 & 4.8 & 4.16 & 4.64 & $1.8-6.0$ & 2.60 \\
\hline 4. & Cloud point $\left({ }^{\circ} \mathrm{C}\right)$ & 12 & 2 & 7 & -2 & 5 & - & -3 \\
\hline 5. & Pour point $\left({ }^{\circ} \mathrm{c}\right)$ & 8 & -3 & 4 & -5 & 2 & - & -8 \\
\hline 6. & Flash point $\left({ }^{\circ} \mathrm{c}\right)$ & 235 & 230 & 180 & 185 & 170 & $130 \mathrm{~min}$ & 50 \\
\hline 7. & Fire point $\left({ }^{\circ} \mathrm{C}\right)$ & 245 & 240 & 190 & 195 & 182 & $135 \mathrm{~min}$ & 60 \\
\hline
\end{tabular}




\subsection{Density}

The density of raw Jatropha oil is higher than the other fuels as shown in Figure 7 . The density is calculated at room temperature $\left(20^{\circ} \mathrm{C}\right)$.

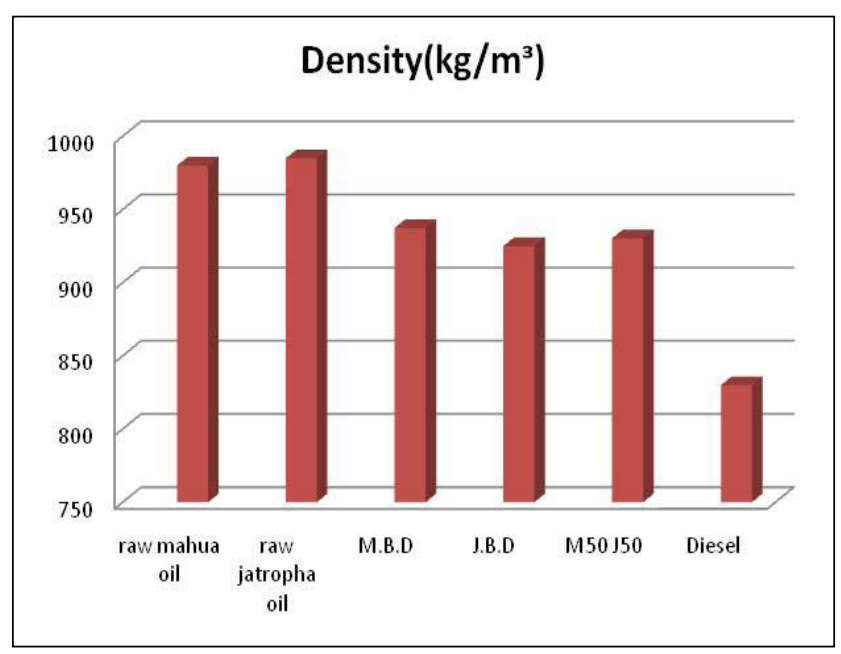

Figure 7. Comparison of density.

\subsection{Specific Density}

The specific gravity of Jatropha oil is higher than the other fuels as shown in Figure 8.

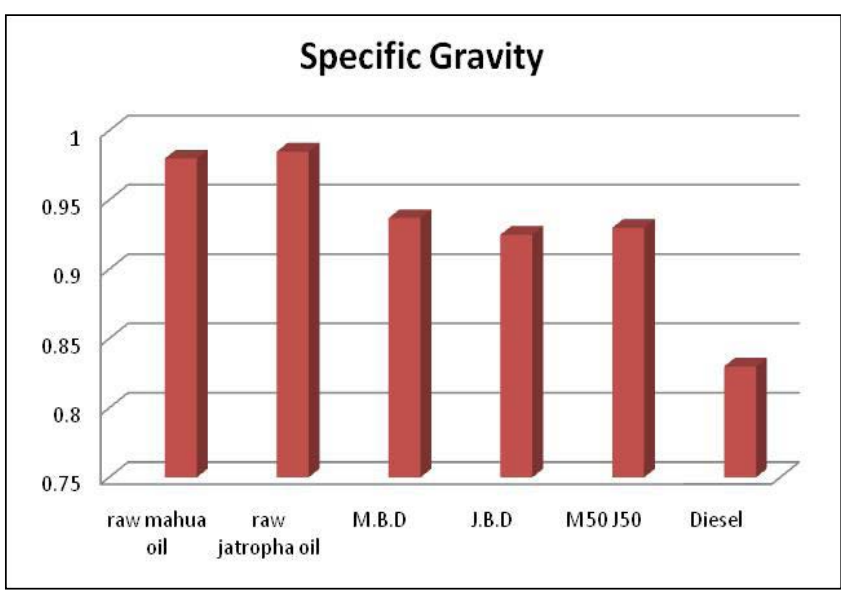

Figure 8. Comparison of specific gravity.

\subsection{Kinematic Viscosity}

Kinematic viscosity of raw Mahua oil is greater than the other fuels as shown in Figure 9. It is calculated at $40^{\circ} \mathrm{C}$ with the help of redwood viscometer.

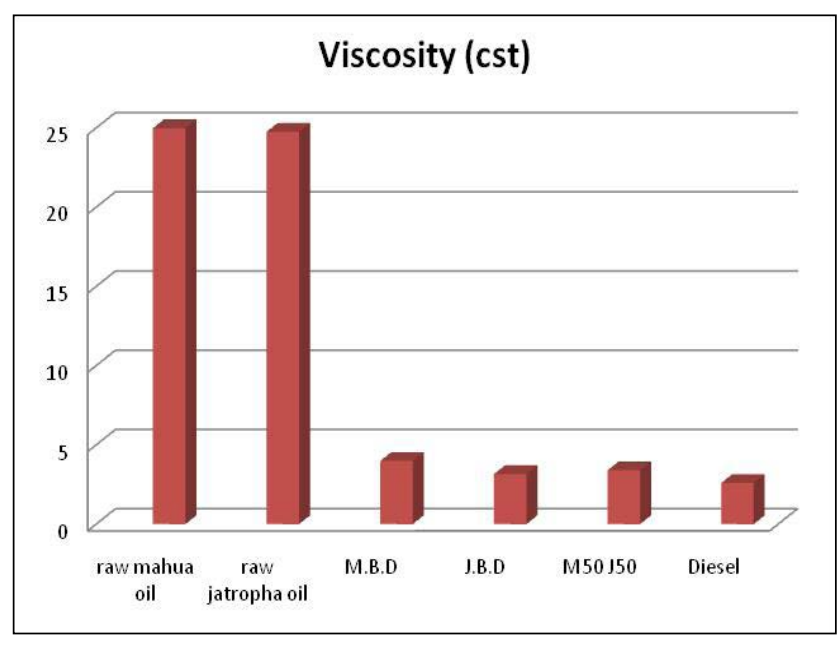

Figure 9. Comparison of viscosity.

\subsection{Flash Point}

The temperature at which the vapor of fuels catches fire when ignited is flash point. Flash point of Mahua seed oil is higher than the others as shown in Figure 10. Flash point is calculated with the help of penskey martins close cup apparatus.

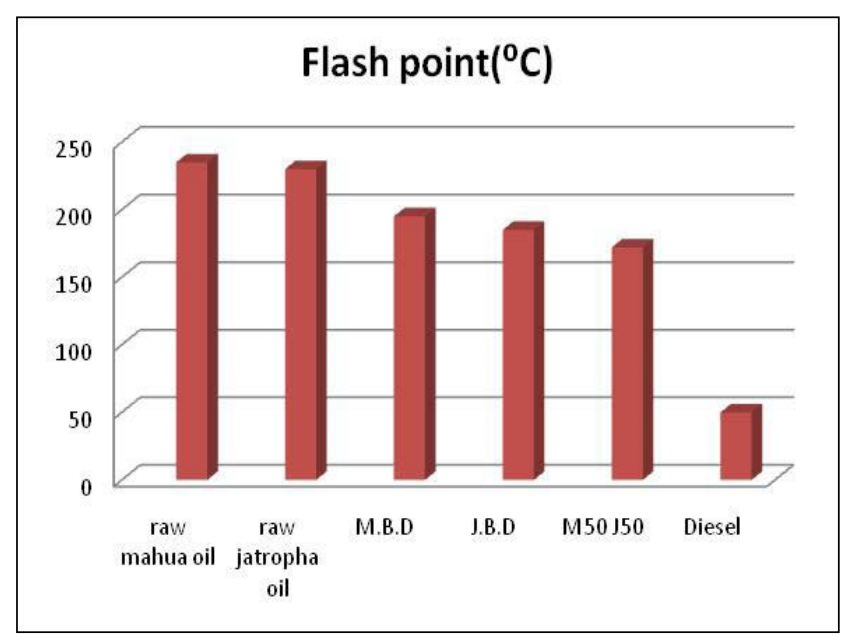

Figure 10. Comparison of flash point.

\subsection{Fire Point}

Fire point is the temperature at which the sample burn continuously for a span of at least 5 seconds; Mahua seed oil has the highest fire point among the other fuel samples as shown in Figure 11. Pensky Martins apparatus is used to find the fire point. 


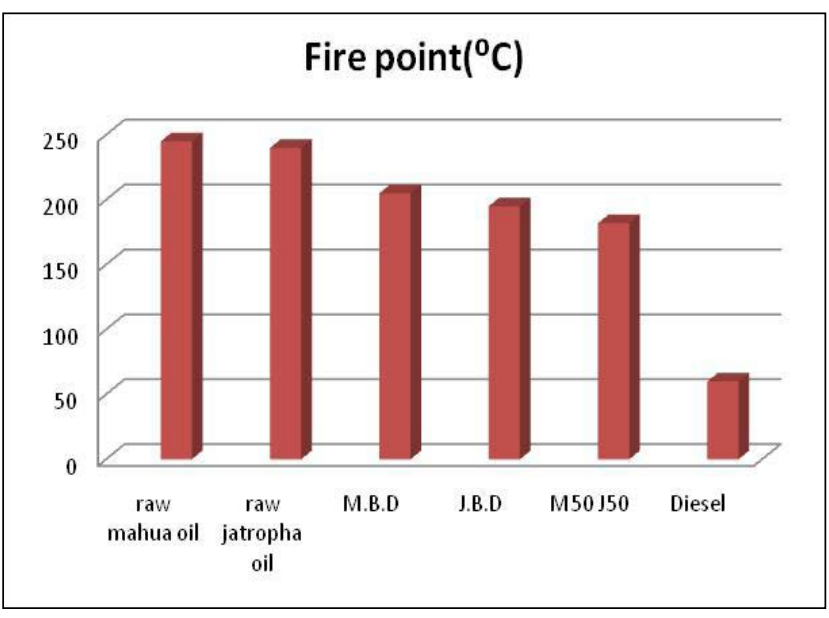

Figure 11. Comparison of fire point.

\subsection{Cloud Point}

Cloud point of Jatropha biodiesel is lower than Mahua biodiesel and the cloud point of M50 J50 is better than Mahua biodiesel as shown in Figure 12, which results in better cold flow properties.

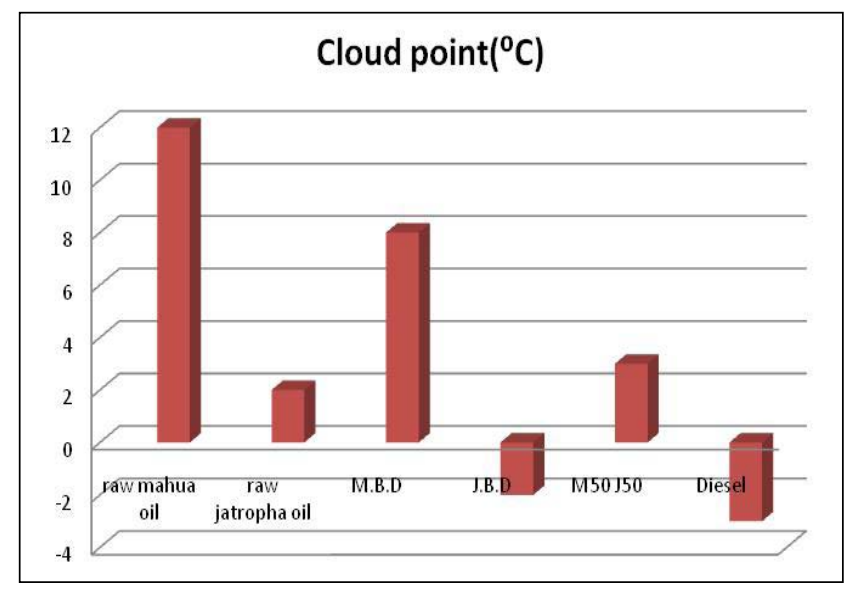

Figure 12. Comparison of cloud point.

\subsection{Pour Point}

Pour point of Jatropha biodiesel is better than that of the Mahua biodiesel, the pour point of the M50 J50 is better than Mahua biodiesel as shown in Figure 13. As the pour point of M50 J50 is better it would leads towards the better cold flow properties.

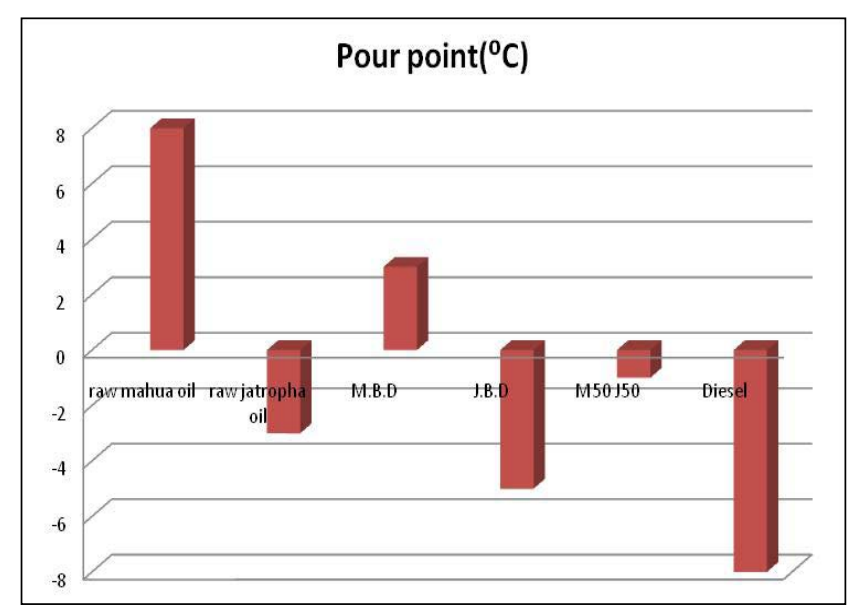

Figure 13. Comparison of pour point.

\section{Conclusion}

In the research work, weve found out various results which are as follows:

- The raw seed oil of Mahua and Jatropha have prominent free fatty acid content that to improve their physio chemical properties they are required to be processed through pre treatment before the actual transesterification process.

- Jatropha and Mahua biodiesel have better compensating physio chemical properties so they can be blended to produce dual fuel.

- M50 J50 has good cold flow characteristics than Mahua biodiesel and other blends.

- The cold flow characteristics of the blended dual fuel are 39.28\% better than Mahua biodiesel.

- Cold flow properties of the biodiesel can be improved by adding another biodiesel into it.

This work can be further extended to the testing of the dual fuel on the single cylinder diesel engine to analysis the combustion behavior and emissions characteristics.

\section{Acknowledgement}

This project work was supported by Department of Automobile Engineering, Chandigarh University, Mohali (Punjab). Authors would like to acknowledge the help 
offered by Department of Automobile Engineering, Department of Chemical Engineering, Chandigarh University and technical help by Mr. Navdeep Sharma Dugala, Coordinator of Automobile Engineering Department, Mr. Mohd. Aslam Associate Professor and Mr. Charansingh, Lab Technician at Chandigarh University, Mohali.

\section{References}

1. Ashraful AM, Masjuki HH, Kalam MA, Rizwanul Fattah IM, Imtenan S, Shahir SA, Mobarak SM. Production and comparison of fuel properties, engine performance and emission characteristics of biodiesel from various nonedible vegetable oils: A review. Energy Conversion and Management. Research Direct Library. 2014; 80:202-28. Crossref

2. Demirbas A. Progress and recent trends in biodiesel fuels. Energy Conversion and Management. 2009; 50(1):14-34. Crossref

3. Srithar K, Arun Balasubramanian K, Pavendan V, Ashok Kumar B. Experimental investigations on mixing of two biodiesels blended with diesel as alternative fuel for diesel engines. Journal of King Saud University - Engineering Sciences. 2017; 29:50-6.

4. Berchmans HJ, Hirata S. Biodiesel production from crude Jatropha curcas L. seed oil with a high content of free fatty acids. Bioresource Technology. 2008; 99:1716-21. PMid: 17531473. Crossref

5. Rathore Y, Ramchandani D. Mahua Biodiesel: An alternative to conventional diesel fuel. IOSR Journal of Mechanical and Civil Engineering (IOSR-JMCE). 2016. p. 42-51. PMid: 26941529 PMCid: PMC4753754.

6. Padhi SK, Singh RK. Optimization of esterification and transesterification of Mahua (Madhuca Indica) oil for production of biodiesel. Journal of Chemical and Pharmaceutical Research. 2010; 2(5):599-608.

7. Sarath Babu RT, Kannan M, Lawrence P. Evaluation of Mahua oil biodiesel and its blends on performance and emission characteristics of diesel engine. International Journal of Advanced Engineering Technology. 2016; 7(2):1188-90.

8. Puhan S, Vedaraman N, Rambrahaman BV, Nagarajan G. Mahua (madhucaindica) seed oil: A source of renewable energy in India. Journal of Scientific and Industrial Research. 2005; 64:890-6.

9. Ghadge SV, Raheman H. Biodiesel production from Mahua (Madhucaindica) oil having high free fatty acids. Biomass and Bioenergy. 2005; 28:601-5. Crossref

10. Kuthalingam AB, Asokan G, Marta V, Skryabin I, Karuppiah S. Performance and emission characteristics of double biodiesel blends with diesel. Thermal Science. 2013; 17(1):255-62.

11. Musa IA. The effects of alcohol to oil molar ratios and the type of alcohol on biodiesel production using transesterification process. Egyptian Journal of Petroleum. 2016; 25:21-31. Crossref 